Int. J. Electrochem. Sci., 11 (2016) $9402-9412$

\title{
Electrocatalytic Oxidation of Formic Acid in Acid Medium at Pd Electrodeposited onto $\mathrm{TiO}_{2}$ Nanotubes
}

\author{
J. Aldana-González, ${ }^{1,2}$, J. Uruchurtu-Chavarin' ${ }^{2}$, M. G. Montes de Oca ${ }^{1}$, M. T. Ramírez-Silva , \\ M. Palomar-Pardavé, M. Romero-Romo ${ }^{1, *}$ \\ ${ }^{1}$ Universidad Autónoma Metropolitana Azcapotzalco. Departamento de Materiales, Av. San Pablo \\ \#180, Col. Reynosa-Tamaulipas, CDMX, C.P. 02200, Mexico \\ ${ }^{2}$ Universidad Autónoma del Estado de Morelos. CIICAP. Av. Universidad No. 1001, Col. Chamilpa, \\ Cuernavaca. C.P. 62209, Morelos, México. \\ ${ }^{3}$ Universidad Autónoma Metropolitana-Iztapalapa, Departamento de Química, Av. San Rafael Atlixco \\ \#186, Col. Vicentina, CDMX, C.P. 09340, Mexico \\ *E-mail: $\underline{\text { mmrr@correo.azc.uam.mx }}$
}

doi: $10.20964 / 2016.11 .54$

Received: 6 July 2016 / Accepted: 9 September 2016 / Published: 10 October 2016

$\mathrm{TiO}_{2}$ nanotubes were electrolytically formed on a Ti surface after which Pd was electrodeposited for different times. The electrodes thus produced were evaluated for the $\mathrm{HCOOH}$ electro-oxidation in an acid aqueous solution. It is shown that the $\mathrm{HCOOH}$ oxidation current density varies as a function of the Pd electrodeposition time. The best performing electrode was that achieved after 1200 seconds Pd electrodeposition.

Keywords: Palladium; $\mathrm{TiO}_{2}$ nanotubes; formic acid; oxidation.

\section{$\underline{\text { FULL TEXT }}$}

(C) 2016 The Authors. Published by ESG (www.electrochemsci.org). This article is an open access article distributed under the terms and conditions of the Creative Commons Attribution license (http://creativecommons.org/licenses/by/4.0/). 